\title{
Setting the stage: host invasion by HIV
}

Florian Hladik $^{* \ddagger \S}$ and M. Juliana McElrath* ${ }^{* \neq}$

Abstract | For more than two decades, HIV has infected millions of people worldwide each year through mucosal transmission. Our knowledge of how HIV secures a foothold at both the molecular and cellular levels has been expanded by recent investigations that have applied new technologies and used improved techniques to isolate ex vivo human tissue and generate in vitro cellular models, as well as more relevant in vivo animal challenge systems. Here, we review the current concepts of the immediate events that follow viral exposure at genital mucosal sites where most documented transmissions occur. Furthermore, we discuss the gaps in our knowledge that are relevant to future studies, which will shape strategies for effective HIV prevention.

HIV vaccines and microbicides hold promise for preventing the acquisition of HIV-1 and HIV-2, the two viruses that cause AIDS, but the success of designing such agents needs a clear understanding of where HIV first encounters its target cells - primarily T cells, macrophages and dendritic cells (DCs) - and how it gains entry at various sites to eventually establish infection. HIV infection has rapidly spread since the early 1980 s to become an epidemic disease (see the UNAIDS/WHO AIDS epidemic update) that is largely maintained by sexual transmission through the lower genital and rectal mucosa (FIG. 1, TABLE 1). Here, we have endeavoured to assemble the current knowledge on the acquisition of HIV at mucosal sites, confining our discussion to the lower genital mucosa. We clearly recognize that other sites of entry, such as the blood, placenta and gastrointestinal mucosa (BOX 1), are also important for HIV acquisition but these are beyond the scope of this Review.

Many studies have provided insights into certain aspects of HIV and simian immunodeficiency virus (SIV) mucosal entry by carrying out detailed examinations of the relevant tissues and target cells following their in vivo, ex vivo or in vitro exposure to the virus. This Review discusses experimental systems that use the same mucosal source to avoid confusion and the inconsistencies that often emerge when findings from one system are extrapolated to those of another. Where appropriate, we have emphasized the benefits and limitations of the experimental approaches, important considerations in the interpretation of findings and their relevance for future studies.

\section{HIV invasion in the female genital tract}

Anatomical sites. An estimated 30-40\% of all new HIV-1 infections in women occur through vaginal intercourse, which carries a lower HIV transmission probability per exposure event than anal intercourse or parenteral inoculation (TABLE 1). Although HIV-1 can infect the vaginal, ectocervical and endocervical mucosa (FIG. 1), the relative contribution of each site to the establishment of the initial infection is not known. The multilayered squamous epithelium that covers the vagina and ectocervix, when intact, provides better mechanical protection against HIV invasion than the singlelayer columnar epithelium that lines the endocervix. However, the greater surface area of the vaginal wall and ectocervix, which often exceeds 15 times that of the endocervix, provides more potential access sites for HIV entry, particularly when breaches occur in the epithelial-cell layer. HIV or SIV can establish an initial infection solely through invasion of the vaginal mucosa, as shown in women who lack a uterus at birth ${ }^{1}$ and in female macaques after surgical removal of the uterus ${ }^{2}$. In fact, selective transmission of HIV through the vaginal mucosa rather than the cervix may commonly occur, as suggested by a recent large, randomized, controlled, prevention clinical trial in African women. In this study, no significant reduction in HIV-1 acquisition occurred in women using a diaphragm compared with the control group ${ }^{3}$. However, the observed potential benefit of blocking HIV-1 exposure to the cervix may have been undermined because the sexual partners of the women in the group using a diaphragm reported lower condom use than those in the control group.

The region where the ectocervix transforms into the endocervix (FIG. 1) can have enriched $\mathrm{CD} 4^{+} \mathrm{T}$-cell populations and therefore may be a particularly susceptible site for HIV entry. Whether HIV can cross the endocervical mucus plug, reach the uterine cavity and 
a

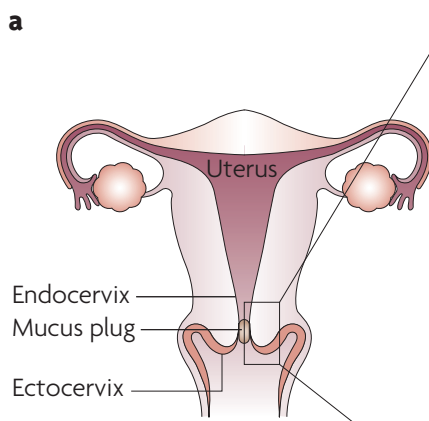

Vagina

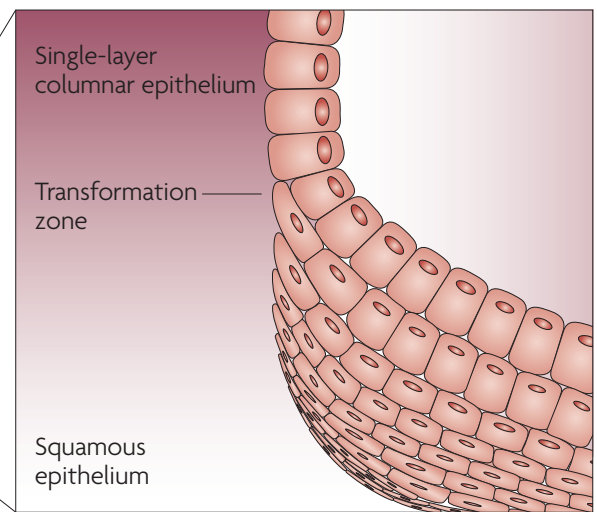

b

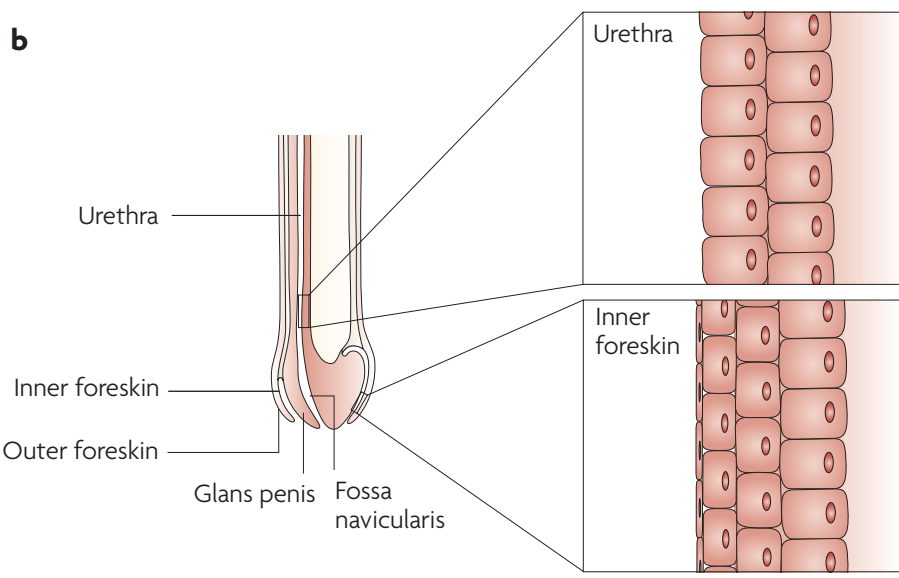

Figure 1 | HIV invasion sites. a | In women, viral invasion occurs mostly through the non-keratinized squamous epithelium of the vagina and ectocervix, as well as through the single-layer columnar epithelium of the endocervix. The endocervical canal is filled with mucus, providing a barrier against the ascent of pathogens. However, ovulation is accompanied by hydration and alkalinization of the mucus plug, possibly decreasing its barrier function. Infection in women can also ensue when HIV-1 invades the singlelayer columnar epithelium of the rectum following receptive anal intercourse. $\mathbf{b}$ | In men, viral invasion occurs most frequently through the inner foreskin and the penile urethra as a consequence of penile-vaginal or penile-anal intercourse. Thinly stratified columnar epithelial cells line most of the urethra except for the fossa navicularis near the external meatus (exit hole), which is covered by non-keratinized squamous epithelium. The glans penis and the outer foreskin are protected by keratinized squamous epithelium, which provides a strong mechanical barrier against HIV invasion. By contrast, a thin and poorly keratinized squamous epithelium covers the inner foreskin, rendering this site vulnerable to HIV invasion. Men are also infected by viral invasion through the rectum.

Simian-HIV

(SHIV). SHIVs are chimeric viruses that are created by inserting the envelope protein (Env), the transcriptional transactivator (Tat) and the regulator of virion gene expression (Rev) of HIV into the SIV $_{\text {MAC239 }}$ clone. Depending on the particular HIV Env protein, these SHIVs have different in vivo characteristics. The SHIV chimeric viruses are best used for testing antibodies specific for HIV in non-human primate models. invade through the mucosa of the upper genital tract has not been well examined. In principle, uterine tissue is susceptible to infection if directly inoculated with HIV $^{4}$. Uterine simian-HIV (SHIV) infection has been shown in one monkey following vaginal inoculation two days earlier, an interval that is probably too short for stromal or lymphatic spread from the lower genital tract ${ }^{5}$. This indicated that ascent of the virus through the endocervical mucus plug may be possible, but this observation has not been confirmed in humans. Conceivably, the upper mucosal tract may become more vulnerable to HIV-1 penetration during ovulation, a period when rising oestrogen levels alter the endocervical mucus making its consistency less viscous and more alkaline.
HIV entry through the female genital epithelium. Both free and cell-associated HIV and SIV virions can establish mucosal infection (FIG. 2) ${ }^{6-10}$. This has been shown directly in vivo in female macaques ${ }^{11}$ and in mice ${ }^{12}$, and indirectly in humans through genetic sequence comparisons of viral isolates from acutely infected women with those from seminal leukocytes (cell-associated virions) and plasma from their infected source partners ${ }^{13}$. Ex vivo studies using human cervical explants have also confirmed transmission of cell-free and cell-associated HIV-1 (REFS 14,15). Initially, cervical mucus can trap infected seminal cells or free virions ${ }^{16,17}$. Conceivably, this could facilitate viral transmission by prolonging contact time of the virions with the mucosa. However, while immobilized, the virions may also become more susceptible to innate antiviral substances.

HIV virions that are initially free, or those that are released from infected donor seminal cells, interact with epithelial cells and traverse the epithelium through several pathways, including transcytosis, endocytosis and subsequent exocytosis, by causing productive infection, or merely by penetrating through the gaps between epithelial cells (FIG. 2). The understanding of these events has been hindered by inconsistent findings, and these are largely a result of the use in experimental systems of epithelialcell types derived from different anatomical sites, as well as primary and immortalized cell lines. Several reports have shown that HIV-1 binds to and enters epithelial cells from the lower female genital tract ${ }^{18-20}$. Transcytosis has been shown to occur in cell lines and also in primary cells, but this has not been definitively shown in intact tissue. On release from the epithelial cells, the virions readily infect susceptible leukocytes ${ }^{21,22}$. Interestingly, cell-associated virions secreted from infected seminal leukocytes appear markedly more efficient at transcytosis than cell-free virions ${ }^{7,10,21}$. It has been reported that virions can also productively infect the cervical epithelial cells themselves ${ }^{6}$, although this remains controversial ${ }^{18,23}$. Conceivably, HIV-1 can also be transported through the cervicovaginal epithelium to the draining lymphatics by donor lymphocytes and macrophages, as has been suggested in mouse studies ${ }^{6,24}$.

Our ex vivo experiments using sheets of isolated vaginal epithelium, devoid of mucosal stroma, confirmed that HIV-1 virions are sequestered in endocytic compartments and in the cytosol of epithelial cells (FIG. 3). Interestingly, although the experimental conditions permitted HIV-1 access to both the luminal and basal sides of the epithelium, the virions were detected exclusively in the basal and suprabasal epithelial cells (F.H., P. Sakchalathorn and M.J.M., unpublished observations). This suggests that initially, rather than entering and traversing superficial epithelial cells in the vagina and ectocervix, HIV-1 probably disperses through the narrow gaps between them ${ }^{16}$, as depicted in FIG. 2. This route might then permit HIV-1 to directly contact and infect intraepithelial Langerhans cells (LCs) and CD4 ${ }^{+} \mathrm{T}$ cells ${ }^{25}$ (see later), or it might allow HIV-1 to reach suprabasal or basal epithelial cells that are more susceptible to viral sequestration and transcytosis. Importantly, components of human semen, most notably amyloid fibrils that form 


\begin{tabular}{|c|c|c|c|c|c|}
\hline $\begin{array}{l}\text { HIV invasion } \\
\text { site }\end{array}$ & $\begin{array}{l}\text { Anatomical } \\
\text { sub-location }\end{array}$ & Type of epithelium & Transmission medium & $\begin{array}{l}\text { Transmission } \\
\text { probability per } \\
\text { exposure event }\end{array}$ & $\begin{array}{l}\text { Estimated contribution } \\
\text { to HIV cases worldwide }\end{array}$ \\
\hline \multirow{2}{*}{$\begin{array}{l}\text { Female genital } \\
\text { tract }\end{array}$} & Ectocervix & Squamous, non-keratinized & \multirow{2}{*}{ Semen } & \multirow{2}{*}{1 in $200-1$ in 2,000} & \multirow{2}{*}{12.6 million } \\
\hline & Endocervix & Columnar, single layer & & & \\
\hline \multirow[t]{3}{*}{$\begin{array}{l}\text { Male genital } \\
\text { tract }\end{array}$} & Inner foreskin & $\begin{array}{l}\text { Squamous, poorly } \\
\text { keratinized }\end{array}$ & \multirow[t]{3}{*}{$\begin{array}{l}\text { Cervicovaginal and rectal } \\
\text { secretions and desquamations }\end{array}$} & \multirow[t]{3}{*}{1 in $700-1$ in 3,000} & \multirow[t]{3}{*}{10.2 million $^{\ddagger}$} \\
\hline & Penile urethra & Columnar, stratified & & & \\
\hline & Other & Various & & & \\
\hline \multirow[t]{2}{*}{ Intestinal tract } & Rectum & Columnar, single layer & Semen & 1 in $20-1$ in 300 & 3.9 million $^{\S}$ \\
\hline & Upper GI tract & Various & Breast milk & 1 in $5-1$ in 10 & $960,000^{\|}$ \\
\hline Placenta & Chorionic villi & $\begin{array}{l}\text { Two layer epithelium (cyto- } \\
\text { and syncytiotrophoblast) }\end{array}$ & Maternal blood (intrauterine) & 1 in $10-1$ in 20 & $480,000^{\|}$ \\
\hline Blood stream & & & Blood products, sharps & 95 in $100-1$ in 150 & 2.6 million" \\
\hline
\end{tabular}

Transcytosis

The process of transport of

material, including HIV virions,

across a cell layer by uptake on

one side of the cell into a

coated vesicle. The vesicle

might then be sorted through

the trans-Golgi network and

transported to the opposite

side of the cell, where its

contents are released into the

extracelluar space.

Langerhans cell

(LC). A type of dendritic cell

that is localized in the

squamous epithelial layer of

the skin and certain mucosae.

Syndecans

Single transmembrane domain

proteins that carry three to five heparan sulphate and

chondroitin sulphate chains

that allow for interaction with

various ligands including

residues on the HIV-1 gp 120

protein. from naturally occurring fragments of seminal prostatic acidic phosphatase, can capture virions and promote their attachment to epithelial cells and leukocytes, thus increasing infectivity ${ }^{26}$.

Several proteins expressed on the surface of epithelial cells may mediate the attachment of HIV-1. Two cellsurface glycosphingolipids, sulphated lactosylceramide expressed by vaginal epithelial cells ${ }^{27}$ and galactosylceramide expressed by ectocervical epithelial cells ${ }^{18,28}$, bind HIV-1 gp120 and foster transcytosis ${ }^{21}$. Interactions of HIV-1 gp120 with transmembrane heparan sulphate proteoglycans (syndecans) expressed by genital epithelial cells can also contribute to HIV-1 attachment and entry $^{19,22}$. Recently, gp340, a splice variant of salivary agglutinin that is expressed by cervical and vaginal epithelial cells, was shown to specifically bind to the HIV envelope protein and to enhance the passage of
HIV through the epithelium giving it access to susceptible leukocytes ${ }^{29}$. One research group found that the $\beta_{1}$ subunit of integrins expressed by cervical epithelial cells from some explants, but not all, bound virions that were presumably coated with fibronectin, which is abundant in human semen ${ }^{16}$. Detection of HIV-1 chemokine co-receptor expression has been inconsistent: one study did not detect the expression of either CC-chemokine receptor 5 (CCR5) or CXC-chemokine receptor 4 (CXCR4) by cervical epithelial cells ${ }^{18}$, another reported the expression of CXCR 4 by these cells ${ }^{20}$, whereas another reported the exclusive expression of CCR5 (REF. 28).

Regardless of the mode, the penetration of virus through the cervicovaginal epithelium in vivo occurs rapidly within 30-60 minutes of exposure, as shown in SIV-infected macaques ${ }^{30}$. Once within the epithelium,

\section{Box 1 | HIV invasion in the gastrointestinal tract}

HIV-1 and simian immunodeficiency virus (SIV) infection commonly targets the lower gastrointestinal tract as an initial infection site following receptive anal intercourse in humans and direct inoculation in macaques, and as a secondary infection site following rapid dissemination from mucosal foci ${ }^{17}$ or acute systemic infection ${ }^{117-119}$. The rectal mucosa contains simple columnar epithelial cells, and the lamina propria is a rich source of lymphoid cells and lymphoid nodules. Numerous reports have documented the pathogenic effect of the virus in the gastrointestinal tract, and have shown a severe depletion of $\mathrm{CD}^{+} \mathrm{T}$ cells that express CC-chemokine receptor 5 (CCR5; an HIV co-receptor) in the gut, regardless of the route of infection ${ }^{116}$. The relevant target cells for infection in the lower gastrointestinal tract are thus likely to be primarily $\mathrm{CD}^{+}$ memory T cells ${ }^{120}$. At present, detailed features of HIV-1 entry into the lower gastrointestinal tract that may be distinct from the genital tract have not been elucidated, but this remains an important question to address for prevention strategies.

The upper gastrointestinal tract, lined by non-keratinized squamous epithelium in the oropharynx and the oesophagus, and by single-layer columnar epithelium in the stomach and the small intestine, is another site of mucosal HIV invasion. In adults, transmission in the upper gastrointestinal tract occurs following contact with HIV-containing semen during fellatio, but the efficiency of this route is low. In infants, HIV invasion in the upper gastrointestinal tract occurs after exposure to or ingestion of infected maternal blood and genital secretions during birth, as well as infected milk during breast feeding. 
A

Epithelial cell Lactosylceramide
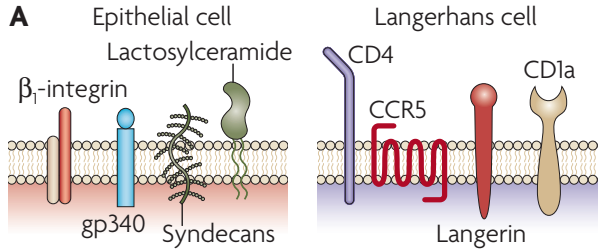

Stromal dendritic cell

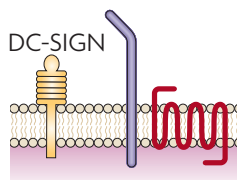

Activated memory T cell Resting memory T cell

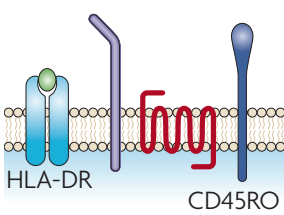

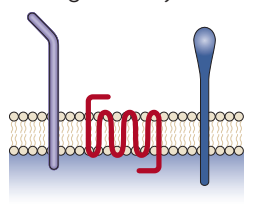

B

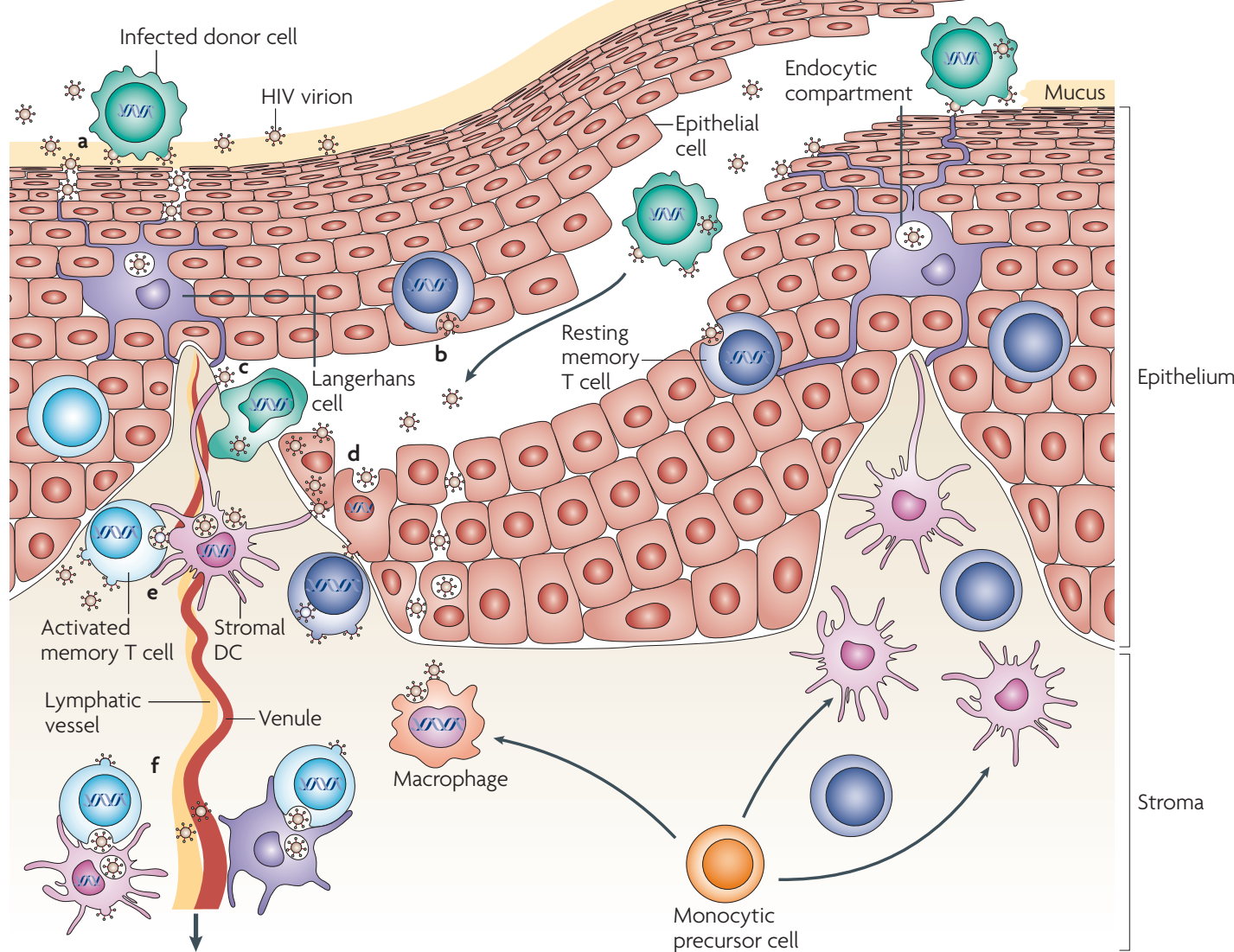

Figure 2 | Pathways of HIV invasion in the mucosa of the vagina and uterine ectocervix. The human vagina and ectocervix are covered by non-keratinized squamous epithelium. Shearing during sexual intercourse can lead to physical abrasions of the epithelium, in particular in microanatomical regions where the stromal papillae, which are enriched with stromal dendritic cells (DCs), reach close to the luminal surface of the mucosa. Monocytic precursor cells differentiate on arrival either into macrophages or DCs, and DCs may differentiate further into subsets. Three stromal DC subsets have been identified in human skin, distinguished by blood DC antigen 1 (BDCA1), CD1 and CD14 expression patterns ${ }^{64}$, but their presence and susceptibility to HIV have not been determined in the mucosa. Infected donor cells and free virions may migrate along the abrasion and directly contact various target cells in the mucosal epithelium and stroma. Resident mucosal leukocytes such as DCs and $T$ cells tend to cluster in these regions, creating susceptible foci for infection. Characteristic phenotypic cell receptors and receptors relevant for HIV binding and infection are shown on the top of the figure (A). The possible pathways of HIV penetration are summarized in B. a | Free HIV virions or HIV-infected donor cells are trapped in mucus, resulting in penetration of the free virions into gaps between epithelial cells or attachment of HIV-infected donor cells to the luminal surface of the mucosa and secretion of virions on contact. The virions are then captured and internalized into endocytic compartments by Langerhans cells that reside within the epithelium. $\mathbf{b} \mid \mathrm{HIV}$ can also fuse with the surface of intraepithelial CD4 ${ }^{+} \mathrm{T}$ cells, followed by productive infection of these cells. c | Infected donor cells or free virions can immigrate along physical abrasions of the epithelium into the mucosal stroma. There they are taken up by lymphatic or venous microvessels and transported to local lymph nodes or into the blood circulation, respectively, or they make contact with stromal DCs, T cells and macrophages. d | Virions can transcytose through epithelial cells near or within the basal layer of the squamous epithelium (see also Figure 3), productively infect basal epithelial cells, be internalized into endocytic compartments, or penetrate between epithelial cells. e | Once within the stroma, virions can productively infect stromal DCs or be internalized into the endocytic compartments of DCs and pass from the stromal DCs to CD4 ${ }^{+} T$ cells across an infectious synapse (see also Figure 4) where massive productive infection of $C D 4^{+} T$ cells ensues. In addition, virions can productively infect resting mucosal $C D 4^{+}$memory $T$ cells in the stroma and possibly stromal macrophages. $\mathbf{f} \mid$ Productively infected $C D 4^{+} T$ cells and stromal DCs, and stromal DCs or intraepithelial LCs harboring virions in endocytic compartments, can emigrate into the submucosa and the draining lymphatic and venous microvessels. CCR5, CC-chemokine receptor 5; DC-SIGN, dendritic-cell-specific ICAM3-grabbing non-integrin. 
Stromal papillae

Superficial areas of the mucosal stroma that epithelium.

C-type lectin receptors A large family of receptors that bind glycosylated ligands and cell adhesion, endocytosis, natural-killer-cell target recognition and dendritic-cell activation.

R5-tropic HIV-1 An HIV strain that uses CC-chemokine receptor 5 (CCR5) as the co-receptor to gain entry to target cells. interdigitate with the have multiple roles, such as in

HIV encounters CD4 ${ }^{+} \mathrm{T}$ cells as well as LCs. LCs have dendrites that extend and retract through the intercellular spaces ${ }^{31}$, and which can even reach up to the surface of the epithelium ${ }^{32}$, where HIV can bind directly to them (T. Hope, personal communication). Based on observations of gut $\mathrm{DCs}^{33,34}$, this could also be particularly true for DCs that are located just beneath the endocervical columnar epithelium. However, direct sampling of luminal pathogens by endocervical DCs or vaginal LCs, which could be exploited by HIV to bypass the epithelialcell barrier, has not yet been formally demonstrated.

Mechanical micro-abrasions of the mucosal surface induced by intercourse may also allow HIV to directly access target cells, such as DCs, T cells and macrophages, at the basal epithelium and the underlying stroma ${ }^{35}$. Areas above the stromal papillae, where the epithelium is relatively thin and where LCs on the epithelial-cell side (F.H., L. Ballweber and M.J.M., unpublished observations) and T cells and macrophages on the stromal side ${ }^{28}$ congregate, appear particularly vulnerable to viral invasion. Consistent with this notion, in vivo simian immunodeficiency virus (SIV) infection of the genital mucosa of macaques is initially established in a highly focal manner, and continuous seeding from this nidus of infection is crucial for establishing systemic infection ${ }^{17}$. Similarly, chemical micro-abrasions from the use of certain topical microbicides and micro-abrasions due to genital ulcers caused by sexually transmitted diseases (for example, syphilis, chancroid and those caused by herpes simplex virus) are also likely to result in the exposure of vulnerable target cells in the basal epithelium and stroma ${ }^{36}$.

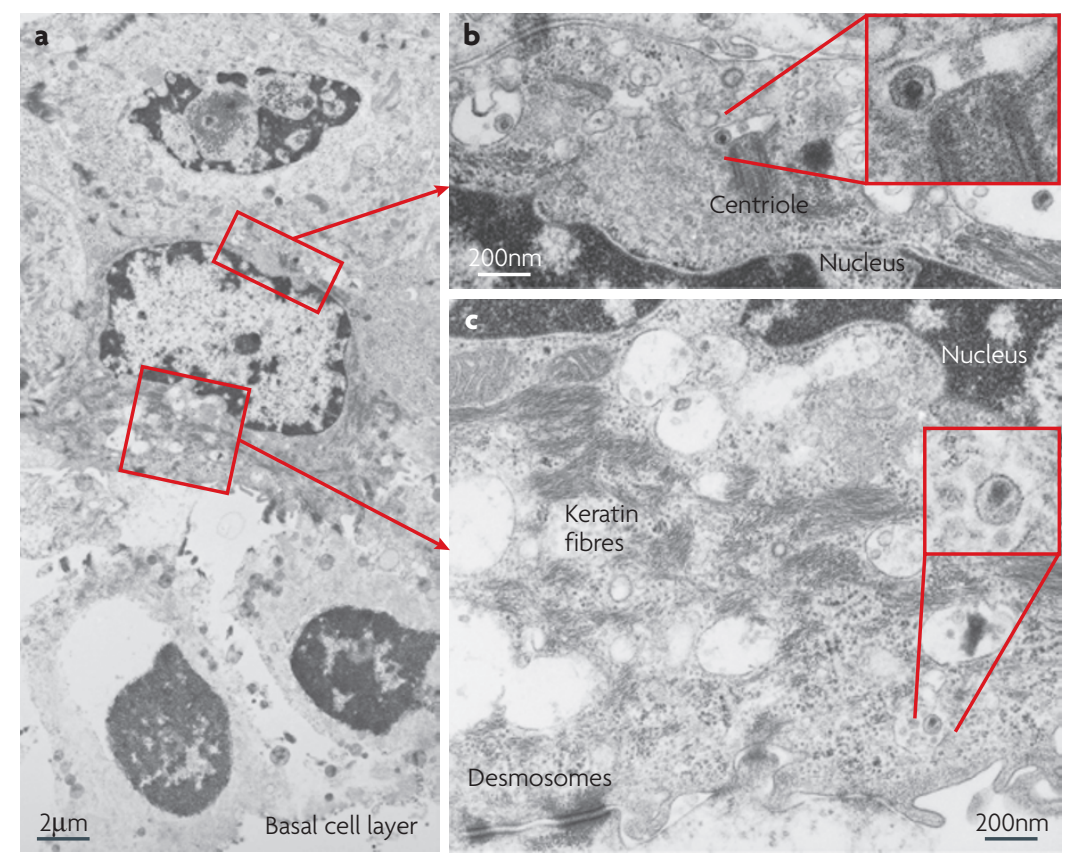

Figure 3 | HIV-1 transcytosis in situ in the vaginal epithelium. Electron micrograph showing a vaginal epithelial cell located one layer above the basal cell layer and containing intact cytoplasmic virions following 24 hours of infection with HIV- $1_{\text {BaL }}$ (a procedure performed on vaginal epithelial sheets, as previously described $\left.{ }^{25}\right)(\mathbf{a})$. As shown in the higher power insets, the virions can be seen on both the apical (b) and basal (c) sides of the nucleus, signifying transcytosis. Desmosomes and keratin fibres, distinguishing features of the epithelial cell, can also be seen (c).
Importance of cervicovaginal LCs in HIV invasion. For many years, HIV-1 invasion of the lower genital tract has been assumed to occur through the internalization of HIV-1 by LCs. This view was supported by evidence that skin LCs are susceptible to infection by HIV-1 (REFS 37-40) and that genital mucosal LCs harbour SIV virions within 24 hours of intravaginal inoculation of macaques ${ }^{30}$. However, soon after ex vivo organ culture, LCs migrate out of the epithelium ${ }^{14,23,41-43}$; therefore, examination of LC infection specifically within the human vaginal epithelium has been technically difficult. For example, one landmark study demonstrated that after exposure of complete cervical mucosa from humans to HIV-1, emigrating DCs had efficiently captured HIV and were capable of transmitting the virus in trans $^{42}$. However, it was not possible to determine whether the cells originated from the epithelium as LCs or from the underlying stroma as DCs. More recently, we resolved this issue by preparing sheets of vaginal epithelium separated from the underlying stroma, and observed that vaginal LCs efficiently internalized HIV-1 into their cytoplasmic compartments $^{25}$. As LCs exit the epithelium at the basal side, they transport intact virions, thereby enabling the infection to spread beyond the site of viral entry (FIC. 2).

However, it is not clear if LCs in the cervicovaginal epithelium can produce and release new HIV-1 virions. HIV receptors expressed by these LCs include CD4, CCR5 and the C-type lectin receptor langerin (also known as CD207), but not CXCR4 and DC-specific ICAM3 (intercellular adhesion molecule 3)-grabbing non-integrin

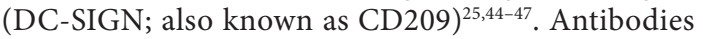
that bind CD4 and CCR5 partially block the uptake of R5-tropic HIV-1 by LCs, but blocking the binding of HIV1 to C-type lectin receptor with mannan, a mannose polymer, had little effect on uptake ${ }^{25}$. Although low-level CD4- and CCR5-mediated productive infection of LCs by HIV-1 in human skin explants has been shown ${ }^{39,40,48}$, we were unable to confirm this finding in our imaging studies of vaginal $\mathrm{LCs}^{25}$. Therefore, if de novo production of virions occurs, it appears relatively inefficient in contrast to the high capacity of vaginal LCs to endocytose HIV-1. Nevertheless, even low levels of productive HIV-1 infection of cutaneous DCs and LCs lead to profound viral replication in co-cultured $\mathrm{T}$ cells ${ }^{40,48,49}$. Therefore, future investigations must conclusively determine if LCs in cervicovaginal epithelium can support productive HIV infection in vivo and if this property is required for the passage of the virus to T cells, as has been reported for other types of $\mathrm{DC}^{50-53}$.

The relative inefficiency of mannan in blocking the binding and endocytosis of HIV-1 by vaginal LCs was surprising ${ }^{25}$ because C-type lectin receptors, which recognize mannose-containing carbohydrate structures, mediate viral entry in other types of DCs ${ }^{46}$. However, HIV-1 can bind DC subsets independent of C-type lectin receptors and CCR5 (REFS 54-56). So, although HIV virions can efficiently bind to langerin expressed by epidermal LCs for their entry into these cells $s^{57}$, they appear to largely bypass binding to langerin expressed by vaginal LCs in favour of alternative endocytic routes. This distinction may be highly relevant for mucosal HIV transmission. 
Langerin expressed by epidermal LCs can direct HIV-1 to Birbeck granules for degradation ${ }^{57}$. By contrast, by gaining entry to the vaginal LCs independently of langerin, HIV may survive by reaching endocytic compartments, such as early phagosomes, where antigens are preserved for cross-presentation ${ }^{58}$. This is consistent with our observations that intact virions were still present in LCs that had migrated out of the vaginal epithelium 60 hours after viral challenge ${ }^{25}$. Therefore, it appears that HIV-1 enters vaginal LCs through a different route than when it enters skin LCs, and this results in a distinct fate of the endocytosed virions. More detailed studies are now warranted to uncover which endocytic pathways HIV uses in vaginal LCs, and how this can be harnessed therapeutically.

Infection of DCs in the cervicovaginal stroma. Unlike genital LCs, stromal DCs express both DC-SIGN ${ }^{46,47}$ and CCR5 (REFS 59,60) and have been implicated in SIV and HIV infection, but their exact role in mucosal transmission is not clear. In situ studies in the human explant model have failed to identify infected DCs in the cervicovaginal stroma ${ }^{14,23,41,43}$. By contrast, SIV-infected DCs were present in the lamina propria of the cervicovaginal mucosa of macaques shortly after intravaginal SIV challenge ${ }^{30,61}$, as well as in chronically infected animals ${ }^{62}$. Likewise, HIV-infected DCs were identified in tissue biopsies of the vaginal stroma of asymptomatic HIV-1-infected women ${ }^{63}$.

The failure to identify infection of stromal DCs in the Membrane-bound rod- or tennis-racket-shaped structures with a central linear density, found in the cytoplasm of Langerhans cells. Their formation is induced by langerin, an endocytic C-type lectin receptor that is specific to Langerhans cells.

\section{Phagosomes}

Vacuolar compartments that confine microorganisms after enforced endocytosis or after phagocytosis. Unless counteracted by a microbial survival strategy, the phagosome matures into a hostile environment that is designed to kill and digest microorganisms.

\section{Cross-presentation}

The initiation of a CD8 ${ }^{+} \mathrm{T}$-cell response to an antigen that is not present within antigenpresenting cells (APCs). This exogenous antigen must be taken up by APCs and then rerouted to the MHC-class-I pathway of antigen presentation.

\section{Lamina propria}

Connective tissue that underlies the epithelium of the mucosa and contains various myeloid and lymphoid cells, including macrophages, dendritic cells, T cells and $B$ cells. of DCs was from the epithelium proper or from the stromal tissue. In addition, inferring the initial susceptibility of DCs while confined to the mucosal stroma, based on findings from emigrated DCs that undergo phenotypic changes as they exit the mucosa, may be less reliable.

Therefore, stromal DCs exhibit different HIV-1 receptor expression patterns compared with LCs, potentially permitting different HIV-1 entry pathways. Much still remains to be learned about stromal DCs in the human genital mucosa in general, whether different subsets exist similar to those found in skin dermis ${ }^{64}$, and the interaction of these DC subsets with HIV virions in particular. More sensitive in situ detection methods of HIV infection, as well as assays that can distinguish de novo virus production from endocytically engulfed virions, as recently reported $^{65}$, will be helpful in determining the exact contribution of stromal DCs to the propagation of HIV.

HIV infection of cervicovaginal $\mathrm{CD}^{+} \mathrm{T}$ cells. $\mathrm{CD} 4^{+}$ $\mathrm{T}$ cells are dispersed throughout the lamina propria of the human vagina, ectocervix and endocervix, often clustering just beneath the basal membrane ${ }^{66,67}$. They are also found at variable numbers within the vaginal and ectocervical squamous epithelium ${ }^{66,67}$. The majority of these cells are memory T cells that express higher levels of CCR 5 than those that circulate in the blood ${ }^{25,68-70}$. One day after HIV-1 inoculation of vaginal, ectocervical and endocervical tissue cultures, infected $\mathrm{CD} 4^{+} \mathrm{T}$ cells were shown to be confined to the mucosal stroma ${ }^{14,16,23,42}$. This result was surprising, given the presence of CCR $5^{+}$ $\mathrm{CD}^{+} \mathrm{T}$ cells within the squamous epithelium. However, by analysing the fate of fluorescently tagged virions as early as 2 hours after viral exposure, we observed that R5-tropic HIV-1 efficiently bound to intraepithelial vaginal $\mathrm{CD}^{+} \mathrm{T}$ cells, and this was followed by fusion and productive infection ${ }^{25}$. Therefore, infected $\mathrm{T}$ cells must rapidly leave the epithelium, and those found in the stroma may be the same or the early progeny of intraepithelial T cells.

Findings in the human explant studies show that HIV-1 very effectively targets $\mathrm{CD} 4^{+} \mathrm{T}$ cells in the genital mucosa for productive infection ${ }^{14,25,42}$, and that the initial infection of intraepithelial $\mathrm{CD}^{+} \mathrm{T}$ cells is probably independent of $\mathrm{LCs}^{25}$. The central role for genital $\mathrm{CD}^{+} \mathrm{T}$ cells in early infection and propagation is also evident from SIV challenge experiments in macaques ${ }^{62,71,72}$. Interestingly, not only does SIV productively infect activated $\mathrm{T}$ cells, characterized by HLA-DR and Ki67 expression, it also infects T cells that are in the resting state (HLA-DR ${ }^{-}$and $\mathrm{Ki}^{-} 7^{-} \mathrm{T}$ cells) ${ }^{71}$. Consistent with this finding, we observed binding of HIV-1 to both HLA-DR ${ }^{+}$and HLA-DR intraepithelial T cells in our human vaginal explant model (M.J.M., P. Sakchalathorn, L. Ballweber and F.H., unpublished observations). In addition, the contribution of resting $\mathrm{CD}^{+} \mathrm{T}$ cells to viral production is substantial during the very earliest stages of infection ${ }^{73}$. The fact that vaginal $\mathrm{CD}^{+} \mathrm{T}$ cells are rapidly depleted following intravenous SIV inoculation of macaques ${ }^{5,72}$, similar to the depletion of $\mathrm{CD}^{+} \mathrm{T}$ cells in the gut during acute SIV infection ${ }^{74}$, further illustrates their high susceptibility to infection in vivo.
Other leukocyte HIV targets in the female genital tract. Macrophages in the female genital mucosa are also susceptible targets for early HIV-1 infection, as demonstrated in studies using human cervical explant models $^{23,41,43}$, and in two reports these cells were the major cell type that was infected by R5-tropic HIV-1 (REFS 23,43). Whether or not resident macrophages in the female genital tract constitutively express CCR5 in situ is not known, but most macrophages do so when harvested from supernatants of vaginal organ cultures ${ }^{60}$, suggesting that the expression of CCR5 by macrophages may occur during the period of activation and emigration from the mucosa ${ }^{75}$. By contrast, SIV-infected macrophages in genital tissues were either rare $^{71}$, or undetectable $e^{30,61}$. Likewise, macrophages in the human intestinal mucosa were reported to lack CCR5 expression and to possess low permissibility to HIV-1 infection ${ }^{76}$. These discrepancies illustrate a potential limitation of organ cultures. If explantation activates stromal macrophages and as a consequence increases surface CCR5 expression, this 

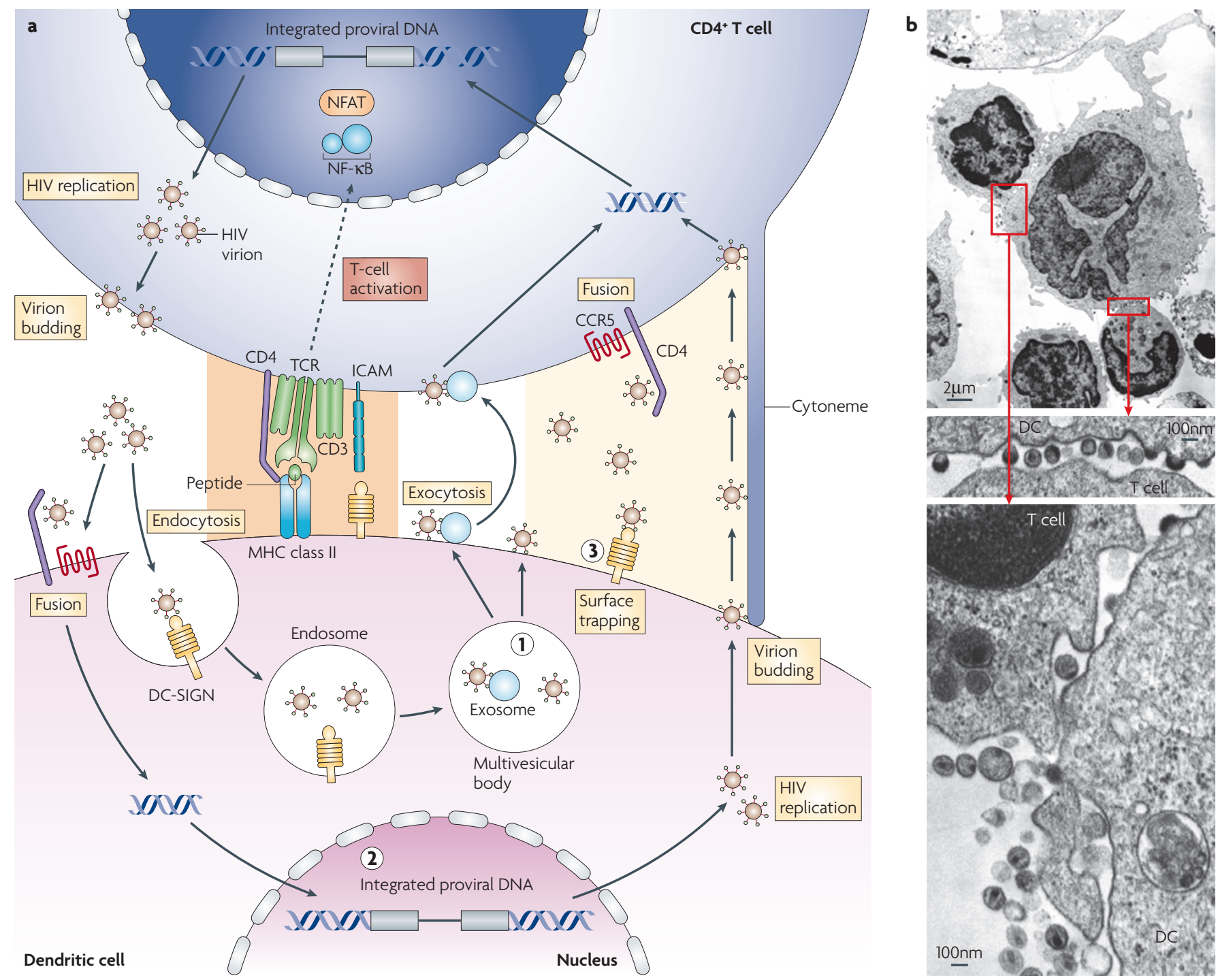

Figure 4 | The significance of DC-T-cell interactions for HIV-1 transmission. a | Pathways of HIV-1 passage between dendritic cells (DCs) and T cells. DCs can store HIV-1 in three forms for eventual infection of CD4 ${ }^{+} T$ cells. (1) HIV can be stored as endocytosed intact virions in multivesicular bodies, following endocytic entry via C-type lectins such as DCspecific ICAM3-grabbing non-integrin (DC-SIGN; also known as CD209). (2) HIV-1 can also be stored as an integrated provirus following entry by CD4- and co-receptor-mediated fusion, which leads to productive infection of DCs. (3) HIV can be stored as surface-bound intact virions by C-type lectins, such as DC-SIGN. Passage of HIV-1 from DCs to CD4 ${ }^{+}$ $T$ cells occurs most effectively across an infectious synapse (yellow shading), formed by a concentration of HIV-1 virions on the DC side and of HIV receptors such as CD4 and CC-chemokine receptor 5 (CCR5) on the T-cell side. HIV is released into the infectious synapse either by exocytosis of stored virions from multivesicular bodies or by budding of newly formed virions following active viral replication. Virions trapped to surface receptors such as the C-type lectin DC-SIGN can also accumulate in the infectious synapse. Migration of HIV toward the T cell may be further enhanced by 'surfing' of virions along the outer surface of filopodia or cytonemes that are extended from the T cell toward the DC. Coupling of virions to exosomes as they are being released from multivesicular bodies also increases their infectivity. Exosome-associated virions are likely to be transmitted to $\mathrm{CD} 4^{+} \mathrm{T}$ cells through membrane binding and fusion, either within the infectious synapse or over longer distances. In parallel with transmission of virus from the DC to the $C D 4^{+} T$ cell, the DC also presents antigenic peptides through MHC class II molecules to the T-cell receptor (TCR). During peptide recognition, additional receptor-ligand pairs that are important for T-cell stimulation accumulate in this region and form an immunological synapse (orange shading). Signals delivered through the immunological synapse lead to T-cell activation, which ultimately causes transcription factors such as nuclear factor- $\mathrm{\kappa B}(\mathrm{NF}-\mathrm{\kappa B})$ and nuclear factor of activated T cells (NFAT) to translocate into the nucleus of the T cell. There, they bind to the enhancer region of the viral long terminal repeat (LTR) and activate viral gene transcription, driving HIV-1 replication. b | Example of infectious-synapse formation between DCs and T cells in the human vagina (images reproduced with permission from REF. 60 ㄷ (1999) American Society For Microbiology). HIV-1 buds from the surface of the productively infected DC toward the contact zone between the DC and the two T cells. Viral budding is also seen along other areas of the DC surface. The DC contains the typical veiled nucleus as well as multiple large mitochondria, and one large cytoplasmic process is formed at the top right. ICAM, intercellular adhesion molecule. 


\section{Macropinocytosis}

A mechanism of endocytosis in which large droplets of fluid are trapped underneath extensions (ruffles) of the cell surface. Can be exploited by some pathogens as a route for entry into cells.

\section{Exosomes}

Small lipid-bilayer vesicles that are released from activated cells. They comprise either plasma membrane or membrane derived from intracellular vesicles

\section{Filopodia}

Slender cytoplasmic projections, which extend from the leading edge of migrating cells.

Cytonemes

Actin-based filopodial-cell extensions.

\section{Nanotubules}

Cytonemes that connect blood cells over a distance of several cell diameters and transport membrane proteins, lipids and ions from one of the connected cells to another, thus executing long range intercellular communications would lead to an overestimation of their susceptibility to infection in vivo. Of note, in addition to allowing virion fusion through their expression of chemokine receptors, monocyte-derived macrophages can also trap intact virions through syndecans ${ }^{77}$, or even without specific envelope-receptor interactions through a process known as macropinocytosis ${ }^{78}$. Once captured, HIV-1 can be stored for several days and then transmitted to $\mathrm{T}$ cells in trans $^{79,80}$. If genital macrophages similarly store infectious virions, their role in viral propagation once HIV-1 invades the stroma could be significant.

Other leukocyte populations also interact with HIV. For example, productive infection of natural killer (NK) cells has been reported ${ }^{81}$, as well as the transmission of HIV through DC-SIGN expressed by B cells to T cells in $\operatorname{trans}^{82}$. The significance of B cells for HIV invasion in the genital mucosa remains unknown. Last, monocyte precursor cells enter the mouse dermis in large numbers following intracutaneous infection with Leishmania major and differentiate into stromal $\mathrm{DCs}^{83}$. This finding raises the possibility that the influx of inflammatory cells into the genital tract following HIV-1 exposure may create new potential target cells that normally do not reside in the mucosa, and further heighten the initial local infection.

The role of DCs in enhancement of infection. A growing body of published literature suggests that HIV exploits DCs to enhance its infectivity of T cells ${ }^{84}$. First reported in 1992, blood-derived DCs that were exposed to HIV-1 invoked vigorous cytopathic infection of co-cultured $\mathrm{CD} 4^{+} \mathrm{T}$ cells, even though infection of the DCs could not be detected ${ }^{85}$. The potential relevance of these findings for the transmission of HIV at mucosal sites was subsequently highlighted by reports of increased HIV-1 replication in DC-T-cell conjugates derived from human skin ${ }^{86}$ and cervicovaginal mucosa ${ }^{60}$. The enhancement of HIV transmission by DCs probably occurred by facilitating T-cell activation ${ }^{71,87}$, as well as de novo T-cell infection.

Four mechanisms for how DCs can augment de novo infection of T cells have been proposed (FIG. 4). In classic HIV trans infection ${ }^{46}$, although the DCs are not productively infected they can trap and preserve the virus and subsequently transfer it to $\mathrm{T}$ cells across an 'infectious synapse', which is a zone of DC-T-cell contact where HIV itself and the HIV host-cell receptors are concentrated ${ }^{88,89}$. Alternatively, trans infection may occur by HIV association with DC-derived exosomes, which, intriguingly, appear to markedly increase the infectivity of virions that are coupled to them ${ }^{90}$. The third mechanism involves the transmission of new viral progeny from productively infected DCs across the infectious synapse to $\mathrm{T}$ cells ${ }^{48,51-53}$. In this case, the contact zone has also been termed a 'virological synapse', to indicate that the donor cell, in analogy to cell-associated HIV transmission between $\mathrm{CD} 4^{+} \mathrm{T}$ cells ${ }^{91}$, is productively infected $^{92}$. Furthermore, efficient retroviral transfer between cells has recently been described, in which retroviruses, including HIV-1, 'surf' along the outer surface of filopodia or cytonemes that extend from an uninfected cell and interact through their tips with an infected cell ${ }^{93}$. These narrow filopodial contact zones may be special cases of virological synapses ${ }^{94}$, or may be analogous to nanotubules that are formed between immune cells ${ }^{95}$. In T cells, migration of HIV-1 also occurs within nanotubules ${ }^{129}$. Nanotubules have been shown to functionally connect DCs with other cells ${ }^{95}$, but their significance for viral transfer from DCs remains to be determined.

Clear evidence for any of these described modes of viral transmission from DCs to $\mathrm{CD}^{+} \mathrm{T}$ cells in the genital mucosa is still lacking. We have shown that HIV concentrates along the cell-cell junction between emigrant LC-T-cell conjugates from human vaginal epithelium, supporting the formation of an infectious synapse ${ }^{25}$. No consensus has been reached over whether in trans infection occurs primarily from surface bound virions $s^{46,96}$, internalized virions ${ }^{97}$ or both ${ }^{56}$. At any rate, once HIV makes its way into the genital DC-T-cell conjugate, a profound productive infection ensues $^{60}$. Of note, in these conjugates viral budding was not only observed from the surface of T cells but also from the surface of the DCs. Visualization of budding by electron microscopy would suggest that the cells are heavily infected with the virus. So, in genital DC-T-cell conjugates not only T cells but also DCs, which alone are generally weak producers ${ }^{84}$, produce large amounts of viral progeny. This is consistent with findings obtained in co-cultures of monocyte-derived DCs and T cells ${ }^{98}$. Therefore, DC-T-cell crosstalk in the genital tract appears to drive productive HIV infection in both cell types. Moreover, transmission from DCs to $\mathrm{T}$ cells may provide a means for HIV to avoid antibodymediated neutralization ${ }^{99-101}$. Taken together, unravelling the precise mechanisms by which the interaction between genital DCs and CD4 ${ }^{+} \mathrm{T}$ cells enhance HIV transmission will be important in developing effective strategies to counteract this process.

\section{HIV invasion in the male genital tract}

Of the nearly 15 million men that are currently infected with HIV-1, an estimated 70-75\% acquired it through vaginal intercourse (TABLE 1), making the male genital tract the second leading site of HIV invasion. HIV-1 target cells are abundant in the foreskin, and include $\mathrm{CD} \mathrm{a}^{+} \mathrm{LCs}$ and $\mathrm{CD} 4^{+} \mathrm{T}$ cells in the squamous lining, as well as T cells, macrophages and DCs in the underlying stroma ${ }^{45,102-104}$. Variable fractions of these cells express CD4, CCR5 and CXCR4 (REFS 45,102,103). As in the vagina, LCs do not express DC-SIGN, whereas at least some of the stromal DCs do ${ }^{102}$. Therefore, similar mechanisms to the ones that have been described for viral invasion of the female genital tract are likely to occur in the male genital tract.

The highly protective effect of circumcision ${ }^{105,106}$, which has been reviewed comprehensively elsewhere ${ }^{107}$, suggests that the penile foreskin is particularly vulnerable to HIV infection. The foreskin is lined by stratified squamous epithelium, and the external surface is more heavily keratinized than the internal surface ${ }^{102,103}$. Consequently, the inner foreskin may be more susceptible 
Glans penis

Sensitive tip of the penis. When the penis is flaccid it is wholly or partially covered by the foreskin, except in men who have been circumcised. to infection, a view that was supported by investigations of penile autopsy tissues ${ }^{102}$, and corroborated in an in vitro foreskin explant model that showed infectious foci, predominantly containing LCs and $\mathrm{CD} 4^{+} \mathrm{T}$ cells, at the base of the epithelial-cell layer, exclusively in the inner foreskin ${ }^{103}$. Alternatively, circumcision may reduce the risk for genital tears, abrasions and ulcer disease, resulting in decreased HIV infection risk ${ }^{107,108}$.

Although circumcision appears to provide a protective effect against HIV infection, in circumcised males, there must be HIV entry sites other than the foreskin. The glans penis has a heavily keratinized squamous epithelium similar to the outer foreskin, and effective viral penetration seems relatively improbable here. By contrast, the penile urethra is a more likely candidate as it is lined by narrowly stratified, non-keratinized columnar epithelial cells and contains high numbers of $\mathrm{CD} 4^{+}$and $\mathrm{CD} 8^{+}$ $\mathrm{T}$ cells, and macrophages, within the epithelium and the lamina propria ${ }^{109}$. Interestingly, DCs are not observed in the urethral mucosa ${ }^{45,109}$. The presence of CCR5 and CXCR4 mRNA in urethral swabs indicates that these HIV-1 co-receptors may be expressed by urethral cells ${ }^{110}$, particularly the predominant $\mathrm{CD} 4{ }^{+} \mathrm{CD} 45 \mathrm{RO}^{+}$memory $\mathrm{T}$ cells ${ }^{109}$. Of note, intraurethral infusion of SIV resulted in infection of all six inoculated male macaques ${ }^{111}$. In men infected with HIV-1, antibiotic treatment of urethral Neisseria gonorrhoeae infection reduces HIV-1 shedding in semen but not the viral load in blood ${ }^{112}$. This finding, as well as HIV-1 shedding in the ejaculate of vasectomized HIV-positive men ${ }^{113}$ and in the pre-ejaculatory fluid ${ }^{114,115}$ suggest a distal viral source, pointing to the urethra as a site harbouring significant numbers of cells susceptible to HIV-1 infection. Taken together, these data suggest that $\mathrm{CD} 4^{+} \mathrm{T}$ cells and macrophages in the male urethra provide a suitable entry portal for HIV, although the specific events of urethral invasion are still unknown.

\section{Conclusions}

Although studies that focus on mucosal HIV infection continue to be painstaking, many investigators have overcome some of the technical difficulties that have previously precluded active research in this area. The recent investigations summarized here provide invaluable insights into the distinct cellular and molecular interactions of mucosal $\mathrm{HIV}$ infection. Clearly, the challenge emerging from these findings is to counteract the rapid acceleration of infection in local reservoirs of the lower genital and gastrointestinal tracts. Two key questions to address in future studies lie in determining whether DC-T-cell interactions that markedly amplify HIV-1 production - which are consistently observed in vitro - are relevant in the mucosal epithelium in vivo, and whether common mechanisms of HIV-1 entry apply to both the lower genital and gastrointestinal tract. This information can guide the development of innovative strategies to protect susceptible target cells from HIV-1 infection in both women and men, such as with barrier protection methods, topical microbicides and mucosal immunization.

Although there is an increasing number of large-scale HIV prevention clinical trials that have recently reported a lack of efficacy, one favourable approach has been male circumcision. The opportunity to gain a more thorough understanding of how HIV-1 invades its target cells in the human foreskin should be exploited. The recent emphasis of $\mathrm{CD} 4^{+} \mathrm{T}$-cell depletion by HIV-1 in the gut and vagina during acute infection has sparked a renewed interest in abating infection at the sites where massive replication occurs ${ }^{116}$. Although important in counteracting HIV disease, $\mathrm{CD} 4^{+} \mathrm{T}$-cell depletion appears to be a secondary event that commonly occurs through various routes of transmission. Therefore, the best opportunity to prevent HIV disease clearly lies at the sites of mucosal entry, and investigations to directly counterattack HIV infection must continue to focus on these portals.
1. Kell, P. D., Barton, S. E., Edmonds, D. K. \& Boag, F. C. HIV infection in a patient with Meyer-RokitanskyKuster-Hauser syndrome. J. R. Soc. Med. 85 706-707 (1992).

2. Miller, C. J., Alexander, N. J., Vogel, P., Anderson, J. \& Marx, P. A. Mechanism of genital transmission of SIV: a hypothesis based on transmission studies and the location of SIV in the genital tract of chronically infected female rhesus macaques. J. Med. Primatol. 21, 64-68 (1992).

3. Padian, N. S. et al. Diaphragm and lubricant gel for prevention of HIV acquisition in southern African women: a randomised controlled trial. Lancet 370 , 251-261 (2007)

4. Howell, A. L. et al. Human immunodeficiency virus type 1 infection of cells and tissues from the upper and lower human female reproductive tract. J. Virol. 71, 3498-3506 (1997)

5. Joag, S. V. et al. Animal model of mucosally transmitted human immunodeficiency virus type 1 disease: intravaginal and oral deposition of simian human immunodeficiency virus in macaques results in systemic infection, elimination of CD4 ${ }^{+} \mathrm{T}$ cells, and AIDS. J. Virol. 71, 4016-4023 (1997).

6. Phillips, D. M., Tan, X., Perotti, M. E. \& Zacharopoulos, V. R. Mechanism of monocyte-macrophage-mediated transmission of HIV AIDS Res. Hum. Retroviruses 14, S67-S70 (1998).

7. Alfsen, A., Yu, H., Magerus-Chatinet, A., Schmitt, A. \& Bomsel, M. HIV-1-infected blood mononuclear cells form an integrin- and agrin-dependent viral synapse to induce efficient HIV-1 transcytosis across epithelial cell monolayer. Mol. Biol. Cell 16, 4267-4279 (2005).
8. Sourisseau, M., Sol-Foulon, N., Porrot, F., Blanchet, F. \& Schwartz, O. Inefficient human immunodeficiency virus replication in mobile lymphocytes. J. Virol. 81, 1000-1012 (2007)

9. Muratori, C. et al. Macrophages transmit human immunodeficiency virus type 1 products to CD4negative cells: involvement of matrix metalloproteinase 9. J. Virol. 81, 9078-9087 (2007).

10. Van Herrewege, Y. et al. A dual chamber model of female cervical mucosa for the study of HIV transmission and for the evaluation of candidate HIV microbicides. Antiviral Res. 74, 111-124 (2007).

11. Kaizu, M. et al. Repeated intravaginal inoculation with cell-associated simian immunodeficiency virus results in persistent infection of nonhuman primates. J. Infect. Dis. 194, 912-916 (2006)

12. Khanna, K. V. et al. Vaginal transmission of cellassociated HIV-1 in the mouse is blocked by a topical, membrane-modifying agent. J. Clin. Invest. 109, 205-211 (2002)

13. Zhu, T. et al. Genetic characterization of human immunodeficiency virus type 1 in blood and genital secretions: evidence for viral compartmentalization and selection during sexual transmission. J. Virol. 70, 3098-3107 (1996).

14. Gupta, P. et al. Memory $\mathrm{CD}^{+}{ }^{+} \mathrm{T}$ cells are the earliest detectable human immunodeficiency virus type 1 (HIV-1)-infected cells in the female genital mucosal tissue during HIV-1 transmission in an organ culture system. J. Virol. 76, 9868-9876 (2002).

15. Zussman, A., Lara, L., Lara, H. H., Bentwich, Z. \& Borkow, G. Blocking of cell-free and cell-associated
HIV-1 transmission through human cervix organ culture with UC781. AIDS 17, 653-661 (2003).

16. Maher, D., Wu, X., Schacker, T., Horbul, J. \& Southern, P. HIV binding, penetration, and primary infection in human cervicovaginal tissue. Proc. Natl Acad. Sci. USA 102, 11504-11509 (2005).

17. Miller, C. J. et al. Propagation and dissemination of infection after vaginal transmission of simian immunodeficiency virus. J. Virol. 79, 9217-9227 (2005).

18. Dezzutti, C. S. et al. Cervical and prostate primary epithelial cells are not productively infected but sequester human immunodeficiency virus type 1 . J. Infect. Dis. 183, 1204-1213 (2001).

19. Wu, Z., Chen, Z. \& Phillips, D. M. Human genital epithelial cells capture cell-free human immunodeficiency virus type 1 and transmit the virus to $\mathrm{CD} 4^{+}$cells: implications for mechanisms of sexual transmission. J. Infect. Dis. 188, 1473-1482 (2003)

20. Berlier, W. et al. Selective sequestration of $X 4$ isolates by human genital epithelial cells: Implication for virus tropism selection process during sexual transmission of HIV. J. Med. Virol. 77, 465-474 (2005).

21. Bomsel, M. Transcytosis of infectious human immunodeficiency virus across a tight human epithelial cell line barrier. Nature Med. 3, 42-47 (1997). This study introduced the concept of HIV-1 transcytosis, a process by which intact virions are transported through the interior of epithelial cells, thereby retaining their infectivity.

22. Bobardt, M. D. et al. Cell-free human immunodeficiency virus type 1 transcytosis through primary genital epithelial cells. J. Virol. 81, 395-405 (2007). 
23. Greenhead, P. et al. Parameters of human immunodeficiency virus infection of human cervical tissue and inhibition by vaginal virucides. J. Virol. 74 5577-5586 (2000).

24. Ibata, B., Parr, E. L., King, N. J. \& Parr, M. B. Migration of foreign lymphocytes from the mouse vagina into the cervicovaginal mucosa and to the iliac lymph nodes. Biol. Reprod. 56, 537-543 (1997).

25. Hladik, F. et al. Initial events in establishing vaginal entry and infection by human immunodeficiency virus type-1. Immunity 26, 257-270 (2007). This investigation found that HIV-1 rapidly penetrates intraepithelial vaginal $C D 1 a^{+}$ Langerhans cells and $\mathrm{CD}^{+} \mathrm{T}$ cells, and that viral fusion predominates in $\mathrm{T}$ cells and viral endocytosis in LCs.

26. Munch, J. et al. Semen-derived amyloid fibrils drastically enhance HIV infection. Cell 131 1059-1071 (2007)

The authors discovered that amyloidogenic fragments of prostatic acidic phosphatase in semen can serve as strong enhancing factors for HIV infection.

27. Furuta, Y. et al. Infection of vaginal and colonic epithelial cells by the human immunodeficiency virus type 1 is neutralized by antibodies raised against conserved epitopes in the envelope glycoprotein gp 120. Proc. Natl Acad. Sci. USA 91, 12559-12563 (1994).

28. Yeaman, G. R. et al. Chemokine receptor expression in the human ectocervix: implications for infection by the human immunodeficiency virus-type I. Immunology 113, 524-533 (2004).

29. Stoddard, E. et al. gp340 expressed on human genital epithelia binds HIV- 1 envelope protein and facilitates viral transmission. J. Immunol. 179, 3126-3132 (2007).

30. Hu, J., Gardner, M. B. \& Miller, C. J. Simian immunodeficiency virus rapidly penetrates the cervicovaginal mucosa after intravaginal inoculation and infects intraepithelial dendritic cells. J. Virol. 74, 6087-6095 (2000).

31. Nishibu, A. et al. Behavioral responses of epidermal Langerhans cells in situ to local pathological stimuli. J. Invest. Dermatol. 126, 787-796 (2006).

32. Miller, C. J., McChesney, M. \& Moore, P. F. Langerhans cells, macrophages and lymphocyte subsets in the cervix and vagina of rhesus macaques. Lab. Invest. 67, 628-634 (1992).

33. Rescigno, M. et al. Dendritic cells express tight junction proteins and penetrate gut epithelial monolayers to sample bacteria. Nature Immunol. 2 361-367 (2001)

34. Niess, J. H. et al. CX $\mathrm{CR} 1$-mediated dendritic cell access to the intestinal lumen and bacterial clearance. Science 307, 254-258 (2005).

35. Norvell, M. K., Benrubi, G. I. \& Thompson, R. J. Investigation of microtrauma after sexual intercourse J. Reprod. Med. 29, 269-271 (1984).

36. Weiler, A. M. et al. Genital ulcers facilitate rapid viral entry and dissemination following intravaginal inoculation with cell-associated $\operatorname{SIV}_{\mathrm{mac}} 239$. J. Virol. 82, 4154-4158 (2008)

37. Tschachler, E. et al. Epidermal Langerhans cells-a target for HTLV-III/LAV infection. J. Invest. Dermatol. 88, 233-237 (1987)

38. Zaitseva, M. et al. Expression and function of CCR5 and CXCR4 on human Langerhans cells and macrophages: implications for HIV primary infection. Nature Med. 3, 1369-1375 (1997).

39. Dittmar, M. T. et al. Langerhans cell tropism of human immunodeficiency virus type 1 subtype $A$ through $F$ isolates derived from different transmission groups. J. Virol. 71, 8008-8013 (1997).

40. Kawamura, T. et al. Candidate microbicides block HIV-1 infection of human immature Langerhans cells within epithelial tissue explants. J. Exp. Med. 192, 1491-1500 (2000).

41. Collins, K. B., Patterson, B. K., Naus, G. J., Landers, D. V. \& Gupta, P. Development of an in vitro organ culture model to study transmission of HIV-1 in the female genital tract. Nature Med. 6, 475-479 (2000)

42. Hu, Q. et al. Blockade of attachment and fusion receptors inhibits HIV-1 infection of human cervical tissue. J. Exp. Med. 199, 1065-1075 (2004). This investigation clearly demonstrates that DCs migrating from HIV-1-exposed cervical tissue can efficiently transmit the virus. Inhibition of this pathway can occur only by simultaneous blockade of CD4 and mannose-binding C-type lectin receptors.
43. Cummins, J. E., Jr et al. Preclinical testing of candidate topical microbicides for anti-human immunodeficiency virus type 1 activity and tissue toxicity in a human cervical explant culture. Antimicrob. Agents Chemother. 51, 1770-1779 (2007).

44. Turville, S. G. et al. Diversity of receptors binding HIV on dendritic cell subsets. Nature Immunol. 3 , 975-983 (2002)

45. Hussain, L. A. \& Lehner, T. Comparative investigation of Langerhans' cells and potential receptors for HIV in oral, genitourinary and rectal epithelia. Immunology 85, 475-484 (1995)

46. Geijtenbeek, T. B. et al. DC-SIGN, a dendritic cellspecific HIV-1-binding protein that enhances transinfection of T cells. Cell 100, 587-597 (2000). In this report, DC-SIGN is identified as an HIV-1 receptor expressed by DCs that promotes efficient infection of $C D 4^{+} \mathrm{T}$ cells in trans.

47. Jameson, B. et al. Expression of DC-SIGN by dendritic cells of intestinal and genital mucosae in humans and rhesus macaques. J. Virol. 76, 1866-1875 (2002).

48. Kawamura, T. et al. Significant virus replication in Langerhans cells following application of HIV to abraded skin: relevance to occupational transmission of HIV. J. Immunol. 180, 3297-3304 (2008).

49. Pope, M., Gezelter, S., Gallo, N., Hoffman, L. \& Steinman, R. M. Low levels of HIV-1 infection in cutaneous dendritic cells promote extensive viral replication upon binding to memory $C D 4^{+} \mathrm{T}$ cells. J. Exp. Med. 182, 2045-2056 (1995)

50. Cameron, P. U. et al. Preferential infection of dendritic cells during human immunodeficiency virus type 1 infection of blood leukocytes. J. Virol. 81 2297-2306 (2007)

51. Nobile, C. et al. Covert human immunodeficiency virus replication in dendritic cells and in DC-SIGN-expressing cells promotes long-term transmission to lymphocytes. J. Virol. 79 5386-5399 (2005)

52. Burleigh, L. et al. Infection of dendritic cells (DCs), not DC-SIGN-mediated internalization of human immunodeficiency virus, is required for long-term transfer of virus to T cells. J. Virol. 80, 2949-2957 (2006)

53. Turville, S. G. et al. Immunodeficiency virus uptake turnover, and 2-phase transfer in human dendritic cells. Blood 103, 2170-2179 (2004).

54. Gummuluru, S., Rogel, M., Stamatatos, L. \& Emerman, M. Binding of human immunodeficiency virus type 1 to immature dendritic cells can occur independently of DC-SIGN and mannose binding C-type lectin receptors via a cholesterol-dependent pathway. J. Virol. 77, 12865-12874 (2003).

55 Boggiano, C. Manel, N. \& Littman, D. R. Dendritic cell-mediated trans-enhancement of human immunodeficiency virus type 1 infectivity is independent of DC-SIGN. J. Virol. 81, 2519-2523 (2007)

56. Wang, J. H., Janas, A. M., Olson, W. J. \& Wu, L. Functionally distinct transmission of human immunodeficiency virus type 1 mediated by immature and mature dendritic cells. J. Virol. 81, 8933-8943 (2007).

57. de Witte, L. et al. Langerin is a natural barrier to HIV-1 transmission by Langerhans cells. Nature Med. 13, 367-371 (2007).

This study showed that HIV-1 captured by the C-type lectin receptor langerin was internalized into Birbeck granules and degraded, therefore preventing HIV-1 transmission by skin LCs.

58. Savina, A. et al. NOX2 controls phagosomal pH to regulate antigen processing during crosspresentation by dendritic cells. Cell 126, 205-218 (2006)

59 Prakash, M., Kapembwa, M. S., Gotch, F. \& Patterson, S. Chemokine receptor expression on mucosal dendritic cells from the endocervix of healthy women. J. Infect. Dis. 190, 246-250 (2004).

60. Hladik, F. et al. Dendritic cell-T-cell interactions support coreceptor-independent human immunodeficiency virus type 1 transmission in the human genital tract. J. Virol. 73, 5833-5842 (1999). This is the first reported observation that DCs isolated from the vaginal mucosa internalize HIV-1 into cytoplasmic endosomes and produce new virions that bud from the cell membrane.

61. Spira, A. I. et al. Cellular targets of infection and route of viral dissemination after an intravaginal inoculation of simian immunodeficiency virus into rhesus macaques. J. Exp. Med. 183, 215-225 (1996).
In this study, intravaginal inoculation of macaques with SIV led to the infection of stromal DCs and cells in the draining lymph nodes within two days.

62. Hu, J., Pope, M., Brown, C., O’Doherty, U. \& Miller, C. J. Immunophenotypic characterization of simian immunodeficiency virus- infected dendritic cells in cervix, vagina, and draining lymph nodes of rhesus monkeys. Lab. Invest. 78, 435-451 (1998).

63. Bhoopat, L. et al. In vivo identification of Langerhans and related dendritic cells infected with HIV-1 subtype $E$ in vaginal mucosa of asymptomatic patients. Mod. Pathol. 14, 1263-1269 (2001).

64. Nestle, F. O. \& Nickoloff, B. J. Deepening our understanding of immune sentinels in the skin. J. Clin. Invest. 117, 2382-2385 (2007).

65. Turville, S. G., Aravantinou, M., Stossel, H., Romani, N. $\&$ Robbiani, M. Resolution of de novo HIV production and trafficking in immature dendritic cells. Nature Methods 5, 75-85 (2008).

66. Johansson, E. L., Rudin, A., Wassen, L. \& Holmgren, J. Distribution of lymphocytes and adhesion molecules in human cervix and vagina. Immunology 96 272-277 (1999)

67. Edwards, J. N. \& Morris, H. B. Langerhans' cells and lymphocyte subsets in the female genital tract. Br. J. Obstet. Gynaecol. 92, 974-982 (1985).

68. Hladik, F., Lentz, G., Delpit, E., McElroy, A. \& McElrath, M. J. Coexpression of CCR5 and IL-2 in human genital but not blood T cells: implications for the ontogeny of the CCR5+ Th 1 phenotype. J. Immunol. 163, 2306-2313 (1999).

69. Zhang, L. et al. In vivo distribution of the human immunodeficiency virus/simian immunodeficiency virus coreceptors: CXCR4, CCR3, and CCR5. J. Virol. 72, 5035-5045 (1998)

70. Prakash, M., Kapembwa, M. S., Gotch, F. \& Patterson, S. Higher levels of activation markers and chemokine receptors on T lymphocytes in the cervix than peripheral blood of normal healthy women. J. Reprod. Immunol. 52, 101-111 (2001)

71. Zhang, Z. et al. Sexual transmission and propagation of SIV and HIV in resting and activated CD4 ${ }^{+} \mathrm{T}$ cells. Science 286, 1353-1357 (1999).

The authors identified $\mathrm{CD} 4^{+} \mathrm{T}$ cells in the macaque genital mucosa as the predominant targets for SIV infection, and they noted that both activated and resting $\mathrm{T}$ cells propagate virus.

72. Veazey, R. S., Marx, P. A. \& Lackner, A. A. Vagina $\mathrm{CD}^{+} \mathrm{T}$ cells express high levels of CCR5 and are rapidly depleted in simian immunodeficiency virus infection. J. Infect. Dis. 187, 769-776 (2003).

73. Zhang, Z. Q. et al. Roles of substrate availability and infection of resting and activated $C D 4^{+} \mathrm{T}$ cells in transmission and acute simian immunodeficiency virus infection. Proc. Natl Acad. Sci. USA 101, 5640-5645 (2004).

74. Picker, L. J. \& Watkins, D. I. HIV pathogenesis: the first cut is the deepest. Nature Immunol. 6, 430-432 (2005).

75 Tuttle, D. L., Harrison, J. K., Anders, C. Sleasman, J. W. $\&$ Goodenow, M. M. Expression of CCR5 increases during monocyte differentiation and directly mediates macrophage susceptibility to infection by human immunodeficiency virus type 1. J. Virol. 72 . 4962-4969 (1998).

76. Meng, G. et al. Lamina propria lymphocytes, not macrophages, express CCR5 and CXCR4 and are the likely target cell for human immunodeficiency virus type 1 in the intestinal mucosa. J. Infect. Dis. 182, 785-791 (2000)

77. Saphire, A. C., Bobardt, M. D., Zhang, Z., David, G. \& Gallay, P. A. Syndecans serve as attachment receptors for human immunodeficiency virus type 1 on macrophages. J. Virol. 75, 9187-9200 (2001)

78. Marechal, V. et al. Human immunodeficiency virus type 1 entry into macrophages mediated by macropinocytosis. J. Virol. 75, 11166-11177 (2001).

79. Sharova, N., Swingler C., Sharkey, M. \& Stevenson, M. Macrophages archive HIV-1 virions for dissemination in trans. EMBO J. 24, 2481-2489 (2005).

80. Groot, F., Welsch, S. \& Sattentau, Q. J. Efficient HIV-1 transmission from macrophages to $T$ cells across transient virological synapses. Blood, 22 February 2008 (doi: 10.1182/blood-2007-12-130070).

81. Harada, H., Goto, Y., Ohno, T., Suzu, S. \& Okada, S Proliferative activation up-regulates expression of CD4 and HIV-1 co-receptors on NK cells and induces their infection with HIV-1. Eur. J. Immunol. 37. 2148-2155 (2007) 
82. Rappocciolo, G. et al. DC-SIGN on B lymphocytes is required for transmission of HIV-1 to T lymphocytes. PLoS Pathog. 2, e70 (2006)

83. Leon, B., Lopez-Bravo, M. \& Ardavin, C. Monocytederived dendritic cells formed at the infection site control the induction of protective T helper 1 responses against Leishmania. Immunity 26 519-531 (2007)

84. Wu, L. \& KewalRamani, V. N. Dendritic-cell interactions with HIV: infection and viral dissemination. Nature Rev. Immunol. 6, 859-868 (2006).

85. Cameron, P. U. et al. Dendritic cells exposed to human immunodeficiency virus type- 1 transmit a vigorous cytopathic infection to CD4+ T cells. Science 257 , 383-387 (1992)

This is the first study demonstrating HIVtransmission from DCs to $\mathrm{CD}^{+}{ }^{+} \mathrm{T}$ cells.

86. Pope, M. et al. Conjugates of dendritic cells and memory T lymphocytes from skin facilitate productive infection with HIV-1. Cell 78, 389-398 (1994). This investigation showed that DCs and T cells derived from human epithelium form stable conjugates which can enhance HIV replication.

87. Geijtenbeek, T. B. et al. Identification of DC-SIGN, a novel dendritic cell-specific ICAM-3 receptor that supports primary immune responses. Cell 100 575-585 (2000)

88. McDonald, D. et al. Recruitment of HIV and its receptors to dendritic cell-T cell junctions. Science 300, 1295-1297 (2003)

The investigators introduce the concept of an infectious synapse between DCs and T cells to which HIV is recruited on the DC side and CD4 and CCR5 on the T-cell side, thus promoting efficient in trans infection.

89. Arrighi, J. F. et al. DC-SIGN-mediated infectious synapse formation enhances X4 HIV-1 transmission from dendritic cells to T cells. J. Exp. Med. 200, 1279-1288 (2004).

90 Wiley, R. D. \& Gummuluru, S. Immature dendritic cellderived exosomes can mediate HIV-1 trans infection. Proc. Natl Acad. Sci. USA 103, 738-743 (2006).

91. Jolly, C. \& Sattentau, Q. J. Human immunodeficiency virus type 1 assembly, budding, and cell-cell spread in T cells take place in tetraspanin-enriched plasma membrane domains. J. Virol. 81, 7873-7884 (2007)

92. Jolly, C. \& Sattentau, Q. J. Retroviral spread by induction of virological synapses. Traffic 5, 643-650 (2004).

93. Sherer, N. M. et al. Retroviruses can establish filopodial bridges for efficient cell-to-cell transmission. Nature Cell Biol. 9, 310-315 (2007). Retroviruses are transmitted between cells not only across large-surface interfaces (infectious synapses) but also through movement along the outer surface of thin filopodial bridges that are extended from the non-infected to the infected cells.

94. Hope, T. J. Bridging efficient viral infection. Nature Cell Biol. 9, 243-244 (2007).

95. Watkins, S. C. \& Salter, R. D. Functional connectivity between immune cells mediated by tunneling nanotubules. Immunity 23, 309-318 (2005).

96. Cavrois, M., Neidleman, J., Kreisberg, J. F. \& Greene, W. C. In vitro derived dendritic cells transinfect CD4 T cells primarily with surface-bound HIV-1 virions. PLoS Pathog. 3, e4 (2007).

97. Kwon, D. S., Gregorio, G., Bitton, N., Hendrickson, W. A. \& Littman, D. R. DC-SIGN-mediated internalization of
HIV is required for trans-enhancement of T cell infection. Immunity 16, 135-144 (2002).

98. Granelli-Piperno, A., Finkel, V., Delgado, E. \& Steinman, R. M. Virus replication begins in dendritic cells during the transmission of HIV-1 from mature dendritic cells to T cells. Curr. Biol. 9, 21-29 (1999)

99. van Montfort, T., Nabatov, A. A., Geijtenbeek, T. B., Pollakis, G. \& Paxton, W. A. Efficient capture of antibody neutralized HIV-1 by cells expressing DC-SIGN and transfer to CD4+ $\mathrm{T}$ lymphocytes. J. Immunol. 178, 3177-3185 (2007)

100. Ganesh, L. et al. Infection of specific dendritic cells by CCR5-tropic human immunodeficiency virus type 1 promotes cell-mediated transmission of virus resistant to broadly neutralizing antibodies. J. Virol. $\mathbf{7 8}$, 11980-11987 (2004)

101. Chen, P., Hubner, W., Spinelli, M. A. \& Chen, B. K. Predominant mode of HIV transfer between T cells is mediated by sustained Env-dependent neutralizationresistant virological synapses. J. Virol. 81 , 12582-12595 (2007)

102. McCoombe, S. G. \& Short, R. V. Potential HIV-1 target cells in the human penis. AIDS 20, 1491-1495 (2006).

103. Patterson, B. K. et al. Susceptibility to human immunodeficiency virus-1 infection of human foreskin and cervical tissue grown in explant culture. Am. J. Pathol. 161, 867-873 (2002).

104. Donoval, B. A. et al. HIV-1 target cells in foreskins of African men with varying histories of sexually transmitted infections. Am. J. Clin. Pathol. 125 386-391 (2006)

105. Meier, A. S., Bukusi, E. A., Cohen, C. R. \& Holmes, K. K. Independent association of hygiene, socioeconomic status, and circumcision with reduced risk of HIV infection among Kenyan men. J. Acquir. Immune Defic. Syndr. 43, 117-118 (2006).

106. Gray, R. H. et al. Male circumcision for HIV prevention in men in Rakai, Uganda: a randomised trial. Lancet 369, 657-666 (2007)

107. Quinn, T. C. Circumcision and HIV transmission. Curr. Opin. Infect. Dis. 20, 33-38 (2007).

108. Wawer, M. J. et al. Rates of HIV-1 transmission per coital act, by stage of HIV- 1 infection, in Rakai, Uganda. J. Infect. Dis. 191, 1403-1409 (2005).

109. Pudney, J. \& Anderson, D. J. Immunobiology of the human penile urethra. Am. J. Pathol. 147, 155-165 (1995).

110. McClure, C. P. et al. HIV coreceptor and chemokine ligand gene expression in the male urethra and female cervix. AIDS 19, 1257-1265 (2005).

111. Miller, C. J. et al. Genital mucosal transmission of simian immunodeficiency virus: animal model for heterosexual transmission of human immunodeficiency virus. J. Virol. 63, 4277-4284 (1989).

112. Cohen, M. S. et al. Reduction of concentration of HIV-1 in semen after treatment of urethritis: implications for prevention of sexual transmission of HIV-1. AIDSCAP Malawi Research Group. Lancet 349 , 1868-1873 (1997)

113. Krieger, J. N. et al. Vasectomy and human immunodeficiency virus type 1 in semen. J. Urol. 159 820-825; discussion 825-826 (1998).

114. Pudney, J., Oneta, M., Mayer, K., Seage, G., 3rd \& Anderson, D. Pre-ejaculatory fluid as potential vector for sexual transmission of HIV-1. Lancet 340, 1470 (1992).

115. Ilaria, G. et al. Detection of HIV-1 DNA sequences in pre-ejaculatory fluid. Lancet 340, 1469 (1992)
116. Brenchley, J. M., Price, D. A. \& Douek, D. C. HIV disease: fallout from a mucosal catastrophe? Nature Immunol. 7, 235-239 (2006).

117. Wang, X. et al. Massive infection and loss of CD4 $T$ cells occurs in the intestinal tract of neonatal rhesus macaques in acute SIV infection. Blood 109 , 1174-1181 (2007)

118. Mattapallil, J. J. et al. Massive infection and loss of memory $\mathrm{CD}^{+} \mathrm{T}$ cells in multiple tissues during acute SIV infection. Nature 434, 1093-1097 (2005).

119. Mehandru, S. et al. Primary HIV-1 infection is associated with preferential depletion of $C D 4^{+} \mathrm{T}$ lymphocytes from effector sites in the gastrointestinal tract. J. Exp. Med. 200, 761-770 (2004).

120. Haase, A. T. Perils at mucosal front lines for HIV and SIV and their hosts. Nature Rev. Immunol. 5 , 783-792 (2005)

121. HIV/AIDS among men who have sex with men, 2007. CDC HIV/AIDS Fact Sheet. Centers for Diseases Control and Prevention, Atlanta. [online] < http://www. cdc.gov/hiv/topics/msm/resources/factsheets/msm.htm >

122. The Global HIV/AIDS pandemic. Morb. Mort. Wkly. Rep. 55, 841-844 (2006).

123. Page-Shafer, K. et al. Risk of HIV infection attributable to oral sex among men who have sex with men and in the population of men who have sex with men. AIDS 16, 2350-2352 (2002).

124. Aceijas, C., Stimson, G. V., Hickman, M. \& Rhodes, T. Global overview of injecting drug use and HIV infection among injecting drug users. AIDS 18 2295-2303 (2004)

125. Lehman, D. A. \& Farquhar, C. Biological mechanisms of vertical human immunodeficiency virus (HIV-1) transmission. Rev. Med. Virol., 381-403 (2007).

126. Galvin, S. R. \& Cohen, M. S. The role of sexually transmitted diseases in HIV transmission. Nature Rev. Microbiol. 2, 33-42 (2004).

127. Royce, R. A., Sena, A., Cates, W., Jr. \& Cohen, M. S Sexual transmission of HIV. N. Engl. J. Med. 336 1072-1078 (1997)

128. Halperin, D. T. Heterosexual anal intercourse: prevalence, cultural factors, and HIV infection and other health risks, Part I. Aids Patient Care STDS 13, 717-730 (1999).

129 Sowinski et al. Membrane nanotubes physically connect T cells over long distances presenting a novel route for HIV-1 transmission. Nature Cell Biol. 10 211-219 (2008)

Acknowledgements

We thank L. Ballweber and P. Sakchalathorn for electron microscopy and P. Stegall for editorial assistance. This work was supported by the US National Institutes of Health grants AI51980, HD51455, and the James B. Pendleton Trust.

Competing interests statement

The authors declare no competing financial interests.

FURTHER INFORMATION

M. Juliana McElrath's homepage: http://www.fhcrc.org/ science/clinical/clinical faculty.html Centers for disease control and prevention, USA http://www.cdc.gov/hiv/default.htm UNAIDS: http://www.unaids.org/en/KnowledgeCentre/ HIVData/EpiUpdate/EpiUpdArchive/2006/Default.asp ALL LINKS ARE ACTIVE IN THE ONLINE PDF 